\title{
Laboratory diagnosis for Covid-19: A mini-review
}

\author{
Juliana Lemos Dal Pizzo[ [1], Vanusa Pousada da Hora ${ }^{[1]}$, Ana Júlia Reis ${ }^{[1]}$, \\ Júlia Vianna ${ }^{[1]}$, Ivy Ramis ${ }^{[1]}$, Andrea von Groll ${ }^{[1]}$ and Pedro Almeida da Silva ${ }^{[1]}$
} [1]. Universidade Federal do Rio Grande, Núcleo de Pesquisa em Microbiologia Médica,
Programa de Pós-Graduação em Ciências da Saúde, Rio Grande, RS, Brasil.

\begin{abstract}
Coronavirus disease (COVID-19) is a pandemic caused by a new coronavirus, called SARS-CoV-2. This disease was first identified in December 2019 and rapidly developed into a challenge to the public health systems around the world. In the absence of a vaccine and specific therapies, disease control and promotion of patient health are strongly dependent on a rapid and accurate diagnosis. This review describes the main laboratory approaches to making a diagnosis of COVID-19 and identifying those previously infected with SARS-CoV-2.
\end{abstract}

Keywords: COVID-19. Diagnostic. Serology. Molecular. Biomarkers.

\section{INTRODUCTION}

Rapid and accurate diagnosis of Coronavirus disease (COVID-19) is essential for pandemic control as well as for establishing an adequate therapeutic strategy to reduce morbidity and mortality. For both epidemiological and clinical purposes, several methodological approaches have been developed. In this article, we will cover the main laboratory methods and protocols that have been used for the control and management of COVID-19.

\section{USING LABORATORY DIAGNOSIS TO ENHANCE THE CONTROL OF COVID-19}

Reliable laboratory diagnosis represents one of the main tools for the promotion, prevention, and control of infectious diseases ${ }^{1}$. The diagnostic methods for COVID-19 fall under two main categories: immunological and molecular. Immunological tests can be serological tests that mainly detect antibodies in blood or viral antigens in respiratory secretions, and both can be performed with point-of-care platforms. Regarding molecular tests, they are based on the detection of SARS-CoV-2 RNA mainly in nasopharyngeal samples, which in most cases require adequate laboratory infrastructure. In addition to the cited tests, other laboratory parameters have been used as an aid in the clinical monitoring of patients with COVID-192-4.

\footnotetext{
Corresponding author: Prof. Pedro Almeida da Silva.

e-mail: pedrefurg@gmail.com

(1) https://orcid.org/0000-0003-1666-1295

Received 2 July 2020

Accepted 5 August 2020
}

\section{SEROLOGICAL TESTS}

Serological tests are especially important for the diagnosis of patients with mild to moderate disease, in the absence of molecular diagnostics ${ }^{5}$. These tests can have several benefits, such as estimating the transmissibility and lethality rates, assessing individual and community immunity, and valuing the need and effectiveness of nonpharmaceutical interventions (e.g., social isolation). Furthermore, the plasma of convalescents with high levels of antibody production could be used as a therapeutic support ${ }^{6}$. Several serological tests based on enzyme-linked immunosorbent assay (ELISA), and lateral flow immunochromatography (LFI) devices have been developed by different companies worldwide. $\operatorname{IgM}$ and $\operatorname{IgG}$ antibodies detected on ELISA have more than $95 \%$ specificity in the diagnosis of COVID-19 (18). High titers of IgG antibodies detected by ELISA demonstrate a positive correlation with neutralizing antibodies?

Given their point-of-care characteristics, LFI platforms have been widely used. In general, this method detects IgM and IgG antibodies in approximately 20 minutes, individually or simultaneously. Antibodies to glycoprotein S (spike) are analyzed from blood samples obtained by finger puncture without the need for sophisticated equipment or specialized professionals ${ }^{8}$. However, these tests are purely qualitative and can only indicate the presence or absence of SARS-CoV-2 antibodies ${ }^{5}$. Despite its potential value as a tool for pandemic control, the validation of LFI tests remains challenging ${ }^{9}$. The ability to assess their accuracy (sensitivity and specificity) as well as their ability to monitor immunity over time remains insufficient ${ }^{10}$. 
Another matter of concern is inappropriate interpretation of the result, such as a false understanding that a positive result indicates immunity against the SARS-CoV-2, whereas a positive result on the serological test indicates that the person has come into contact with the virus and developed antibodies, but it is not clear whether these antibodies will provide protection against a reinfection ${ }^{11}$.

Currently, antibody responses against SARS-CoV-2 remain poorly understood, and the clinical usefulness of the serological test is still unclear ${ }^{12}$. Although the detection of $\operatorname{IgM}$ and IgG by ELISA is positive even on the fourth day after the onset of symptoms, high levels of these antibodies are produced in the second and third weeks of the disease ${ }^{5}$. From the time of onset, the IgM antibody titer increases; 2 weeks after the onset of symptoms, both IgG and IgM are present and their levels start to decrease after the fourth week. IgM is notoriously nonspecific, and because it takes weeks to develop specific $\operatorname{IgG}$ responses, serological detection is unlikely to play an active role in case management, with diagnosis/confirmation of late cases of COVID-19 or determining the immunity of health professionals being the exceptions ${ }^{12}$. The acute antibody response to SARS-CoV-2 in 285 patients in China's Hubei province was detected using a chemiluminescence immunoenzymatic test (CLIA). The result showed that the proportion of patients positive for specific $\operatorname{IgG}$ reached $100 \%$ approximately 17 to 19 days after the onset of symptoms. Meanwhile, the proportion of patients with specific IgM reached $94.1 \%$ at 20 to 22 days after the onset of symptoms. Seroconversion to IgG and IgM occurred simultaneously or sequentially, giving an average seroconversion time of 13 days after the onset of symptoms. The study data indicate that serological tests can be complementary, especially in the diagnosis of suspected patients with negative molecular results and also in the search for asymptomatic infections among close contacts ${ }^{13}$.

An interesting aspect is that the most severe cases have higher levels of $\operatorname{IgM}$ and $\operatorname{IgG}$ in than the mild cases ${ }^{14,15}$. In this context, the quantitative detection of antibodies can be an important aid in clinical practice ${ }^{16}$.

It is worth mentioning that the majority of immunoassays for SARS-CoV-2 have immunogenic proteins as their main target: 1) protein $\mathrm{S}$ (spike), which is the most highly exposed viral protein, and 2) nucleocapsid protein $(\mathrm{N})$, which is abundantly expressed during infection ${ }^{17}$. Normally, most antibodies are produced against the most abundant protein present in the virus $(\mathrm{N})$. Therefore, tests that detect antibodies to $\mathrm{N}$ would be the most sensitive. However, the protein $\mathrm{S}$ receptor binding domain (RBD-S) is the host's attachment protein, and antibodies to RBD-S would be very specific and are expected to be neutralizing. In this case, the use of one or both antigens to detect IgG and IgM would result in high sensitivity ${ }^{5,7}$.

\section{MOLECULAR TESTS}

Most molecular tests, unlike serological tests, are performed in a specialized laboratory using cutting-edge equipment and highly qualified staff, so their use is limited. Nasopharyngeal (NP) swabs are considered the standard samples for the detection of SARS-CoV-2. In addition to the NP swabs, the use of samples from the lower respiratory tract (sputum or bronchial lavage) and oropharyngeal (OP) swabs are used as alternatives to improve the biosafety of health care workers ${ }^{18}$. A robust study on the detection of SARS-CoV-2 in different clinical samples involved 205 hospitalized patients from three Chinese hospitals, with a total of 1,070 samples collected. The NP swabs had the highest viral load, although at the time of collection, the stage of disease or the associated clinical history was not available for many of these patients ${ }^{2,19}$. For the detection of SARS-CoV-2 by this technique, samples must be collected when the patient is in the acute phase of infection, preferably up to 5 days after the onset of symptoms ${ }^{20}$. This method has the advantage of being both quantitative and highly specific ${ }^{18}$.

Reverse transcription followed by real-time reverse transcription polymerase chain reaction (RT-PCR) is considered the gold standard for the diagnosis of COVID-19. The first protocol recommended by the WHO was published by Charité Institute, Berlin University, Germany ${ }^{21}$. It is based on TaqMan technology, with indicated primers and probes to detect the RNA-dependent RNA polymerase (RdRp), envelope protein $(\mathrm{E})$, and nucleocapsid protein $(\mathrm{N})$ genes. Subsequently, several in-house methods have been reported by the WHO, and they are being validated in WHO partner laboratories (Table 1).

False-negative results can occur mainly because of inadequate extraction of nucleic acid; poor sample quality; low viral load; sample collection time; incorrect sample storage, transportation, and handling; and PCR inhibition ${ }^{22-24}$.

TABLE 1: List of RT-PCR protocols indicated by the WHO.

\begin{tabular}{lr}
\hline Institute & Gene targets \\
\hline China CDC, China & ORF1ab and N \\
Institute Pasteur, France & Two targets in RdRP \\
US CDC, USA & Three targets in N gene \\
National Institute of Infectious Diseases, Japan & Pancorona and multiple targets, Spike protein \\
Charité, Germany & RdRP, E, N \\
HKU, Hong Kong SAR & ORF1b-nsp14, N \\
National Institute of Health, Thailand & $\mathrm{N}$ \\
\hline
\end{tabular}

(Source: https://www.who.int/who-documents-detail/molecular-assays-to-diagnose-COVID-19-summary-table-of-available-protocols) 
Results of different RT-PCRs protocols have shown variation in their performance depending on the primers and probes. One comparative study of the sensitivity of SARS-CoV-2 RT-PCR tests developed by Charité (Germany), HKU (Hong-Kong), China CDC (China), US CDC (United-States), and Institut Pasteur, Paris (France) showed that all RT-PCR assays performed well for SARS-CoV-2 detection, but the authors pointed out that the assays of RdRp Institut Pasteur (IP2, IP4), N China CDC, and N1 US CDC were the most sensitive ${ }^{25}$.

The use of specific primers determines the high specificity of RT-PCR, and the possibility of false-positives cannot be excluded. In this sense, a negative template control should be introduced in every RT-PCR ${ }^{26}$. A chest computerized tomography $(\mathrm{CT})$ scan can be used as a complementary diagnostic tool that enables physicians to effectively detect COVID-19 infection in several RT-PCR false-negative cases. Repeat tests can be particularly important if the patient has a clinical picture of viral pneumonia, history of exposure, and/or radiographic findings (CT or magnetic resonance imaging) compatible with COVID-19 pneumonia ${ }^{12}$.

The development of new diagnostic platforms can improve molecular methods in terms of speed, sensitivity, and accessibility in the diagnosis of COVID-19. Currently, approximately 11 molecular devices have received urgent approval from the National Administration of Medical Products in China ${ }^{18}$. In addition, automated RT-PCR systems have been developed, such as the Xpress SARS CoV-2 Test (Cepheid, USA). Using the GeneXpert platform, SARS-CoV-2 E and N2 genes can be detected in approximately 45 minutes. Another innovative alternative is the Abbott ID Now COVID-19 handheld instrument, which detects the SARS-CoV-2 RdRp and N genes. Both Xpress SARS-CoV-2 and Abbott ID Now COVID-19 were authorized for emergency use by the Food and Drug Administration (FDA), USA ${ }^{27,28}$.

However, with the global shortage of kits, many countries have begun to carry out in-house RT-PCR to overcome this shortage. The most frequently used in-house protocols are as follows: 1) Hospital Charité - University of Berlin that targets the genes E, N and $\mathrm{RdRp}^{21}$, endorsed by the WHO, 2) CDC-China, which targets the ORF1 ab and N genes (CDC-CHINA 2020), and 3) CDC-USA, which uses three targets within the $\mathrm{N}$ gene ${ }^{29}$.

Another molecular approach that may be useful, especially in places where there is no need for expensive thermocycling equipment is reverse transcription loop-mediated isothermal amplification (RT-LAMP) using the SARS-CoV-2 spike ORF1ab and $\mathrm{S}$ genes $^{30,31}$. In addition, the use of biosensors to detect SARSCoV-2 viral RNA has also been tested. The newly developed biosensor integrates the plasmatic photothermal effect and plasmon resonance detection transduction. Validity and selectivity were determined by using the SARS-CoV-2 RdRp and ORF1ab sequences as targets ${ }^{32}$.

\section{BIOSAFETY}

Laboratory testing is a process divided into three main phases: preanalytical, analytical, and postanalytical. In the preanalytical stage, individual protection measures in relation to sample collection are fundamental to good biosafety practices. Based on the WHO guidelines, all clinical samples should be considered potentially infectious, and health professionals must use suitable and a complete set of personal protective equipment (PPE) when obtaining/handling patient samples. Normally, the use of a disposable apron, gloves, bonnet, foot protection, protective goggles, and an N95 breathing mask is expected.

Clinical samples must be transported to the laboratory in packaging appropriate for level-2 biological risk inside a leak-proof cryogenic box and with a clearly visible biohazard label ${ }^{33}$. The samples can be stored at $2-8^{\circ} \mathrm{C}$ for up to 72 hours after collection. If the sample needs to be stored for long, it must be done at a temperature of at least $-70^{\circ} \mathrm{C}$. The extracted nucleic acid must also be stored at the same minimum temperature of $-70^{\circ} \mathrm{C}^{29}$.

Sample processing must be done inside a class-2 biological cabin using suitable clothing and a complete set of PPE. All surfaces, cryo-boxes, and equipment must be cleaned using $0.1 \%$ sodium hypochlorite, $62-71 \%$ ethanol, $0.5 \%$ hydrogen peroxide, and quaternary ammonium or phenolic compounds ${ }^{34}$.

\section{NON-SPECIFIC LABORATORY TESTS}

Results of laboratory tests can increase the support for the diagnosis, prognosis, and monitoring of patients through the detection and measurement of different biomarkers. Although nonspecific, some biomarkers have been reported to be associated with the infectious process of SARS-CoV-2. Therefore, low lymphocyte and platelet counts; low serum albumin levels; and increased serum levels of C-reactive protein, D-dimer, ferritin, lactate dehydrogenase, transaminases, and interleukin- 6 can be used in risk stratification to predict the severity of COVID-1935-39. In addition, cytokine storms with high levels of IL-2R, IL-6, IL-10, and TNF- $\alpha$ and a reduction in the absolute numbers of CD4 + and CD8 + T lymphocytes have been related to severe cases of COVID-19 $9^{40}$, with progression to cardiovascular collapse, multiple organ failure, and rapid deaths ${ }^{41}$.

\section{DISCUSSION}

This review provides an overview of the diagnostic methods used for COVID-19. New studies on this topic are rapidly becoming available in the literature, but there are crucial gaps that prevent an effective response in this pandemic. Although RT-PCR is the most widely used option for diagnosis, it can provide false-negative results, and its use is limited by the requirement of laboratory infrastructure and high $\operatorname{costs}^{22,42,43}$. Molecular point-of-care tests, with high precision, that present fast results, low cost, and easy execution are urgently needed to expand the diagnostic capacity of health systems, especially in low-income settings.

Serological tests can function as complementary tools for the diagnosis of COVID-19. Despite the fact that positive serological results can be obtained around 4-7 days after the onset of the symptoms, their usefulness for patients with viral loads below the detection limit of real-time RT-PCR assays is questionable ${ }^{19}$. These tests are also important to understand the epidemiology of SARS-CoV-2, including the role of asymptomatic infection and current or past infection ${ }^{44}$.

Although diagnosis by real-time RT-PCR is still essential to identify acute SARS-CoV-2 infection, serological tests and 
epidemiological data are necessary to understand past pandemics and predict their future ${ }^{9,10}$. The Global Health Security (GHS) index shows that only $19 \%$ of the countries have the capacity to detect and report epidemics of potential international concern, with fewer than $5 \%$ of the countries having the ability to respond quickly and mitigate the spread of an epidemic. In this sense, it is clear that no country has shown total preparedness for epidemics or pandemics ${ }^{45}$.

The global spread of COVID-19 should help nations establish new and fundamental priorities in the field of research and public health policies. The costs of lives lost and economic crises should serve as stimuli, especially for emerging economies, so that industrial-scale production in the health sector is accelerated and able to meet national requirements.

\section{ACKNOWLEDGMENTS}

We express our deepest thanks to the Universidade Federal do Rio Grande - FURG for supporting the development of this study.

\section{AUTHORS' CONTRIBUTION}

JLDP: Acquisition of data, drafting the article, final approval of the version to be submitted. VPH, AJR, JV and IR: Data acquisition, analysis, and interpretation; final approval of the version to be submitted. AVG: Data acquisition, analysis, and interpretation; final approval of the version to be submitted. PAS: Conception and design of the study, data acquisition, analysis, and interpretation; drafting the article; final approval of the version to be submitted.

\section{FINANCIAL SUPPORT}

\section{CAPES, CNPq, NIH, and FAPERGS. \\ CONFLICT OF INTEREST}

The authors declare no conflict of interest.

\section{REFERENCES}

1. Joynt GM, Wu WK. Understanding COVID-19: what does viral RNA load really mean? Lancet Infect Dis. 2020;20(6):635-6.

2. Cheng VC, Lau SK, Woo PC, Yuen KY. Severe acute respiratory syndrome coronavirus as an agent of emerging and reemerging infection. Clin Microbiol Rev. 2007;20(4):660-94.

3. Ferrari D, Motta A, Strollo M, Banfi G, Locatelli M. Routine blood tests as a potential diagnostic tool for COVID-19. Clin Chem Lab Med. 2020;58(7):1095-9.

4. Rodriguez-Morales AJ, Cardona-Ospina JA, Gutierrez-Ocampo E, Villamizar-Pena R, Holguin-Rivera Y, Escalera-Antezana JP, et al. Clinical, laboratory and imaging features of COVID-19: A systematic review and meta-analysis. Travel Med Infect Dis 2020:101623.

5. Sethuraman N, Jeremiah SS, Ryo A. Interpreting Diagnostic Tests for SARS-CoV-2. JAMA 2020

6. Chen L, Xiong J, Bao L, Shi Y. Convalescent plasma as a potential therapy for COVID-19. Lancet Infect Dis 2020; 20(4):398-400.

7. To KK, Tsang OT, Leung WS, Tam AR, Wu TC, Lung DC, et al. Temporal profiles of viral load in posterior oropharyngeal saliva samples and serum antibody responses during infection by SARS-CoV-2: an observational cohort study. Lancet Infect Dis 2020; 20(5):565-574.

8. Stadlbauer D, Amanat F, Chromikova V, Jiang K, Strohmeier S, Arunkumar GA, et al. SARS-CoV-2 Seroconversion in Humans: A
Detailed Protocol for a Serological Assay, Antigen Production, and Test Setup. Curr Protoc Microbiol 2020; 57(1):e100.

9. Yong SEF, Anderson DE, Wei WE, Pang J, Chia WN, Tan CW, et al. Connecting clusters of COVID-19: an epidemiological and serological investigation. Lancet Infect Dis 2020.

10. Winter AK, Hegde ST. The important role of serology for COVID-19 control. Lancet Infect Dis 2020.

11. WHO. Advice on the use of point-of-care immunodiagnostic tests for COVID-19. In. GENEBRA; 2020.

12. Tang YW, Schmitz JE, Persing DH, Stratton CW. The Laboratory Diagnosis of COVID-19 Infection: Current Issues and Challenges. J Clin Microbiol 2020.

13. Long QX, Liu BZ, Deng HJ, Wu GC, Deng K, Chen YK, et al. Antibody responses to SARS-CoV-2 in patients with COVID-19. Nat Med 2020.

14. Xiao AT, Gao C, Zhang S. Profile of specific antibodies to SARS-CoV-2: The first report. J Infect 2020.

15. Zeng Z, Chen L, Pan Y, Deng Q, Ye G, Li Y, et al. Re: Profile of specific antibodies to SARS-CoV-2: The first report. J Infect 2020.

16. Du Z, Zhu F, Guo F, Yang B, Wang T. Detection of antibodies against SARS-CoV-2 in patients with COVID-19. J Med Virol 2020.

17. Lee CY, Lin RTP, Renia L, Ng LFP. Serological Approaches for COVID-19: Epidemiologic Perspective on Surveillance and Control. Front Immunol 2020; 11:879.

18. Loeffelholz MJ, Tang YW. Laboratory diagnosis of emerging human coronavirus infections - the state of the art. Emerg Microbes Infect 2020; 9(1):747-756.

19. Wang W, Xu Y, Gao R, Lu R, Han K, Wu G, et al. Detection of SARSCoV-2 in Different Types of Clinical Specimens. JAMA 2020.

20. Wolfel R, Corman VM, Guggemos W, Seilmaier M, Zange S, Muller MA, et al. Virological assessment of hospitalized patients with COVID-2019. Nature 2020.

21. Corman VM, Landt O, Kaiser M, Molenkamp R, Meijer A, Chu DK, et al. Detection of 2019 novel coronavirus (2019-nCoV) by real-time RTPCR. Euro Surveill 2020; 25(3).

22. Vashist SK. In Vitro Diagnostic Assays for COVID-19: Recent Advances and Emerging Trends. Diagnostics (Basel) 2020; 10(4).

23. Lv DF, Ying QM, Weng YS, Shen CB, Chu JG, Kong JP, et al. Dynamic change process of target genes by RT-PCR testing of SARS-Cov-2 during the course of a Coronavirus Disease 2019 patient. Clin Chim Acta 2020; 506:172-175.

24. Tahmasebi S, Khosh E, Esmaeilzadeh A. The outlook for diagnostic purposes of the 2019-novel coronavirus disease. J Cell Physiol 2020.

25. Etievant S, Bal A, Escurret V, Brengel-Pesce K, Bouscambert M, Cheynet $\mathrm{V}$, et al. Sensitivity assessment of SARS-CoV-2 PCR assays developed by WHO referral laboratories. medRxiv 2020:2020.2005.2003.20072207.

26. Tahamtan A, Ardebili A. Real-time RT-PCR in COVID-19 detection: issues affecting the results. Expert Rev Mol Diagn 2020; 20(5):453-454.

27. ASM. False Negatives and Reinfections: the Challenges of SARSCoV-2 RT-PCR Testing. In: COVI-19: ASM; 2020.

28. Kim YJ, Sung H, Ki CS, Hur M. COVID-19 Testing in South Korea: Current Status and the Need for Faster Diagnostics. Ann Lab Med 2020; 40(5):349-350.

\section{CDC-EUA. 2020.}

30. Lu R, Wu X, Wan Z, Li Y, Jin X, Zhang C. A Novel Reverse Transcription Loop-Mediated Isothermal Amplification Method for Rapid Detection of SARS-CoV-2. Int J Mol Sci 2020; 21(8). 
31. Yan C, Cui J, Huang L, Du B, Chen L, Xue G, et al. Rapid and visual detection of 2019 novel coronavirus (SARS-CoV-2) by a reverse transcription loop-mediated isothermal amplification assay. Clin Microbiol Infect 2020.

32. Qiu G, Gai Z, Tao Y, Schmitt J, Kullak-Ublick GA, Wang J. DualFunctional Plasmonic Photothermal Biosensors for Highly Accurate Severe Acute Respiratory Syndrome Coronavirus 2 Detection. ACS Nano 2020.

33. Tan SS, Yan B, Saw S, Lee CK, Chong AT, Jureen R, et al. Practical laboratory considerations amidst the COVID-19 outbreak: early experience from Singapore. J Clin Pathol 2020.

34. WHO. Laboratory biosafety guidance related to the novel coronavirus (2019-nCoV), In. WHO; 2020.

35. Chen N, Zhou M, Dong X, Qu J, Gong F, Han Y, et al. Epidemiological and clinical characteristics of 99 cases of 2019 novel coronavirus pneumonia in Wuhan, China: a descriptive study. Lancet 2020; 395(10223):507-513.

36. Di Gennaro F, Pizzol D, Marotta C, Antunes M, Racalbuto V, Veronese N, etal.CoronavirusDiseases(COVID-19)CurrentStatusandFuturePerspectives: A Narrative Review. Int J Environ Res Public Health 2020; 17(8).

37. Frater JL, Zini G, d'Onofrio G, Rogers HJ. COVID-19 and the clinical hematology laboratory. Int J Lab Hematol 2020.
38. Lippi G, Plebani M. Laboratory abnormalities in patients with COVID-2019 infection. Clin Chem Lab Med 2020.

39. Yang X, Yang Q, Wang Y, Wu Y, Xu J, Yu Y, et al. Thrombocytopenia and Its Association with Mortality in Patients with COVID-19. J Thromb Haemost 2020.

40. Chen G, Wu D, Guo W, Cao Y, Huang D, Wang H, et al. Clinical and immunological features of severe and moderate coronavirus disease 2019. J Clin Invest 2020; 130(5):2620-2629.

41. Conti P, Ronconi G, Caraffa A, Gallenga CE, Ross R, Frydas I, et al. Induction of pro-inflammatory cytokines (IL-1 and IL-6) and lung inflammation by Coronavirus-19 (COVI-19 or SARS-CoV-2): antiinflammatory strategies. J Biol Regul Homeost Agents 2020; 34(2).

42. Li R, Pei S, Chen B, Song Y, Zhang T, Yang W, et al. Substantial undocumented infection facilitates the rapid dissemination of novel coronavirus (SARS-CoV2). Science 2020.

43. Zitek T. The Appropriate Use of Testing for COVID-19. West J Emerg Med 2020.

44. Beeching NJ, Fletcher TE, Beadsworth MBJ. Covid-19: testing times. BMJ 2020; 369:m1403.

45. Jia Z, Lu Z. Modelling COVID-19 transmission: from data to intervention. Lancet Infect Dis 2020. 